целостного восприятия мира. Однако, им сложно принимать быстрые, спонтанные решения. Их самооценка зависит от достижений и неудач.

$$
* * *
$$

1. Аветисова, А. А. Психологические особенности игроков в компьютерные игры // Психология. Журнал Высшей школы экономики. - 2011. Т. 8, № 4. С. 37.

2. Бурлаков, И. В. Ното Gamer: Психология компьютерных игр / Библиотека психологии и психотерапии, вып. 86. М.: Независимая фирма «Класс», 2000. - 120 с.

3. Дерманова И. Б., Коростылева Л. А. Психологические проблемы самореализации личности / под ред. А. А. Крылова, Л. А. Коростылевой. СПб: Изд-во С.-Петерб. ун-та, 1997.

4. Беловол Е.В. Разработка опросника для оценки степени увлеченности ролевыми компьютерными играми / Е.В. Беловол, И.В. Колотилова // Психол. журн. - 2011. - Т. 32. - № 6. - С. 49-58.

5. Алешина Ю. Е., Гозман Л.Я., Дубовская Е.М., Загика М.В., Кроз М.В. Измерение уровня самоактуализации личности // Социально-психологические методы исследования супружеских отношений / под ред. Ю.Е. Алешиной, Л.Я. Гозмана, Е.М. Дубовской. - М., 1987. - С. 91-114

6. Кыштымова И.М., Тимофеев С.Б. Психологическая модель компьютерных игр // Социальная психология и общество. 2019. Том 10. № 4. С. 160-174

\title{
Воронин А.Н. \\ Оценка когнитивного ресурса по изменению эффективности решения задач в усложняющихся условиях
}

Институт психологии РАН

(Россия, Москва)

doi: 10.18411/trnio-11-2021-212

\section{Аннотация}

В статье рассматриваются основные подходы к изучению когнитивного ресурса, понимаемого как «протоспособность» когнитивной сферы, инфраструктура интеллекта в самом широком его понимании. Эмпирическая верификация конструкта «когнитивный ресурс» осуществлена через процедуру оценки эффективности решения задач в усложняющихся условиях с использованием онлайн платформы, позволяющей модифицировать проблемное поле. Показано, что у большей части испытуемых уровень познавательных способностей снижается в условиях усложнения ситуации. Однако часть испытуемых сохраняет и/или повышает уровень интеллекта и креативности в затрудненных условиях. Анализ эффективности решения различных типов задач свидетельствует о множественности когнитивных ресурсов: взаимосвязь между изменением эффективности при решении интеллектуальных и креативных задач отсутствует.

Ключевые слова: когнитивный ресурс, интеллект, креативность, познавательные способности, экспериментальная ситуация.

\section{Abstract}

The article discusses the main approaches to the study of a cognitive resource, understood as the "protability" of the cognitive sphere, the infrastructure of intelligence in its broadest sense. Empirical verification of the "cognitive resource" construct was carried out through the procedure for evaluating the effectiveness of solving problems in increasingly complex conditions using an online platform that allows you to modify the problem field. It has been shown that in most of the subjects the level of cognitive abilities decreases in conditions of complication of the situation. However, some of the subjects retained and / or increased the level of intelligence and creativity in difficult conditions. Analysis of the effectiveness of solving various types of problems indicates the multiplicity of cognitive resources: there is no relationship between the change in efficiency when solving intellectual and creative problems. situation.

Keywords: cognitive resource, intelligence, creativity, cognitive ability, experimental 
Широкое понимание психологических ресурсов включает в себя различные психологические свойства и качества человека (способности, умения, «психическая энергия», воля, характер и т.п.) позволяющие противостоять жизненным невзгодам и достигать намеченное несмотря ни на возникающие затруднения. Психологические ресурсы позволяют справиться со сложной жизненной ситуацией и адаптироваться к новым условиям

Концептуально предметная область когнитивного ресурса существенно уже и не связана со всеми психологическими аспектами преодоления проблем отдельным человеком. При определении когнитивного ресурса речь идет о познавательных аспектах решения проблем, о процессе переработки человеком информации. Когнитивный ресурс определяет возможности человека решать разнообразные задачи в условиях различных затруднений. Развивая идею Ч. Спирмена о влиянии общего фактора интеллекта на успешность решения различных тестовых задач и основываясь на представлениях о ресурсах, лимитирующих умственные усилия в зависимости от уровня активации, В.Н. Дружинин ввел понятие "когнитивный ресурс" расширив его значение до обозначения «протоспособности» когнитивной сферы - общего базиса, основания интеллекта в самом широком его понимании [4].

В самом общем виде когнитивный ресурс был определен через множество когнитивных элементов, которые симультанно (одновременно) используются человеком в процессе переработки информации. Когнитивный ресурс был введен как количественная характеристика когнитивной системы, множество связанных когнитивных элементов, которое отвечает за активное создание многомерных моделей реальности в процессе решения задач разного уровня сложности. [4]. Собственно, «когнитивный ресурс» рассматривается как инфраструктура познавательных способностей, в первую очередь интеллекта и креативности. Такой подход объясняет высокую скоррелированность психометрических тестов интеллекта и креативности, описывая их как разные познавательные функции, реализованные на когнитивной инфраструктуре - за счет когнитивного ресурса. Рассмотрение когнитивного ресурса как инфраструктуры познавательных способностей позволяет объяснить различные феномены, связанные с когнитивными искажениями, ситуационными изменениями уровня интеллекта и креативности, уменьшением согласованности когнитивных показателей при повышении уровня интеллекта и т.п. [3].

Для использования конструкта «когнитивный ресурс» в эмпирических исследованиях требуется его верификация путем применения психометрических методов оценки через его операциональные дескрипторы. В обширном эмпирическом исследовании, направленном на изучение взаимосвязей уровня общего интеллекта и различных когнитивных характеристик, включающих и дескрипторы когнитивного ресурса было показано, что показатели иконической и рабочей памяти, время реакции выбора и мерность когнитивного пространства достаточно точно описывают симультанные характеристики когнитивного pecypca [3].

В модели когнитивного ресурса когнитивные способности соответствуют структурам, которые активируются в ходе познавательной деятельности при наличии когнитивного ресурса определенной мощности. Востребованность и распределение когнитивного ресурса зависит как от внутренних факторов (личностных и интенциональных структур), так и от факторов ситуации, ее формальных и содержательных компонентов. Существенно то, что при таком рассмотрении востребованность познавательных способностей определяется средой, в которой решается та или иная задача. Среда выступает как источник информации, как носитель физических свойств и как сфера взаимодействия между людьми. Человек адаптируется к средовым изменениям, выбирая поведение, релевантное текущим событиям. Для оценки среды нами были выделены три параметра: неоднородность, изменчивость и информационная избыточность. В зависимости от степени выраженности состояний среды меняются требования к познавательным ресурсам индивида. В случае высокой неоднородности среды возрастают требования к интеллекту. В ситуации постоянной 
изменчивости повышается необходимый уровень креативности. При высокой степени информационной избыточности возрастают требования к когнитивному ресурсу и интуиции. Гипотетически можно рассмотреть наиболее сложную ситуацию, когда среда характеризуется высокой неоднородностью, изменчивостью и информационной избыточностью, при этом возрастают не только требования к разным познавательным способностям, но и их согласованности. Варьирование сложностью ситуации позволяет «напрямую» оценивать когнитивный ресурс по эффективности решения задач в усложняющихся условиях.

Анализ различных способов варьирования сложностью в тестовых заданиях позволил выделить принципы, приводящие к увеличению когнитивной нагрузки: изменение количества однородных и/или разнородных элементов, включение в задание нерелевантных элементов, увеличение/уменьшение количества логических операций, сочетание разных типов стимульного материала, вариативность условий ответа, временные ограничения на выполнение задания, динамика вариативности условий, изменение количества дистракторов, нетранзитивность объектов и условий, использование контекста разной степени конкретности и др. [2].

Определение основных принципов варьирования сложностью тестовых заданий позволило разработать усложняющие эффекты проблемного поля, приводящие к увеличению когнитивной нагрузки [1]. Наличие таких эффектов позволяет моделировать усложнение ситуации решения познавательных задач и рассматривать ситуацию как независимую переменную, определяющую величину когнитивной нагрузки и степень вовлеченности когнитивного ресурса в процесс решения задачи. Всего было разработано 19 онлайн эффектов (затухание, колебания, изменение размера, «игольное ушко», частичная инверсия, фокусировка, «шторки» и т.д.), усложняющих выполнения интеллектуальных и креативных задач на «проблемном поле» задания. Демоверсия онлайн комплекса представлена на http://cr.solvent-game.ru/cgi-bin/cr_demo.html. Онлайн платформа исследования феноменов КР позволяет настраивать параметры предъявления элементов «проблемного поля» и проводить экспертную оценку визуализации стимульного материала при онлайн обследовании испытуемых с фиксацией времени выполнения отдельных действий и правильности решения. Вклад каждого из эффектов в нагрузку на когнитивный ресурс априори не известен вследствие сочетания различных принципов усложнения в каждом из эффектов. Наиболее часто используемыми принципами являлись: включение в задание нерелевантных элементов, сочетание разных типов стимульного материала, изменение нескольких параметров стимульного материала, например, цвета, формы, ориентации, динамика вариативности условий, увеличение количества дистракторов.

Анализ подходов к оценке ситуационных факторов позволил определить 12 шкал экспертной оценки эффектов, усложняющих ход решения задач. В ходе исследования была выявлена имплицитная структура представлений экспертов о влиянии ситуации на когнитивный ресурс, базирующаяся на 2 факторах: когнитивная нагрузка и встречная активность для прояснения проблемной ситуации. Разработанные онлайн эффекты усложнения проблемной ситуации в ходе экспертной оценки и последующей статистической обработки сгруппировались в 3 кластера: 1 кластер - относительно простые способы повышения когнитивной нагрузки, 2 кластер - сложные и оригинальные эффекты, 3 кластер - эффекты, требующие активных действий и/или манипуляций для изменения визуализации проблемного поля. Все эффекты были упорядочены по степени влияния на когнитивный ресурс, при этом определен вклад каждого из них [1].

Для эмпирической верификации когнитивного ресурса по эффективности решения задач в усложняющихся условиях были сформированы батареи познавательных задач возрастающей сложности. Интеллектуальные задачи представляли собой отдельные пункты тестов SPM Равена, теста I-S-T 2000R Амтхауэра и теста Саймона - всего 30 пунктов. Креативные задания базировались на тесте Медника - 10 пунктов. Батареи познавательных задач последовательно предъявлялись испытуемым с использованием разработанной онлайн платформы. На первом этапе батареи предъявлялись обычным образом. На втором этапе 
батареи предъявлялись с использованием эффектов, усложняющих ситуацию решения. При этом использовались различные эффекты: простые, сложные и требующие активных действий для изменения визуализации проблемного поля. Всего в исследовании приняло участие 208 человек (116 мужчин и 92 женщины, средний возраст 19.78 лет). Исходя из общего представления о когнитивном ресурсе как инфраструктуре познавательных способностей предполагался следующий основной тренд: снижение показателей правильности решения и увеличения разброса при ухудшении условий выполнения задач и их усложнении у большей части испытуемых и относительное сохранение уровня познавательных способностей у незначительной части выборки.

Проведенное исследование показало, что у 69 \% испытуемых результаты в условиях усложнения ситуации выполнения ухудшились, 17\% обследуемых сохранили прежний уровень эффективности решения задач, а $22 \%$ улучшили свои показатели. Показатель изменения в уровне познавательных способностей $\Delta$ (интеллекта и креативности) в усложненных условиях оказался отрицательно связанным с первоначальным уровнем интеллекта. Так корреляция Пирсона между IQ и $\Delta \mathrm{IQ}$ составляет $-0,346$ (значимость на уровне 0.01 ), а между $\mathrm{Cr}$ и $\Delta \mathrm{Cr}$ составляет $-0,446$ (значимость на уровне 0.01 ). При анализе эффективности решения различных типов задач выявлено, что высокий уровень когнитивного ресурса, имеющийся в распоряжении у некоторых испытуемых при решении интеллектуальных заданий не распространяется на решение креативных задач и наоборот: взаимосвязь между $\Delta \mathrm{IQ}$ и $\Delta \mathrm{Cr}$ при усложнении проблемного поля для креативных и интеллектуальных задач отсутствует.

Исследование выполнено при финансовой поддержке РФФИ в рамках научного проекта № 20-013-00495 “Эмпирическая верификаџия структурно-функиииональной модели когнитивного ресурса".

$$
* * *
$$

1. Воронин А.Н., Горюнова Н.Б. Экспертная оценка ситуационных факторов, повышающих нагрузку на когнитивный ресурс при решении познавательных задач // Психология. Историко-критические обзоры и современные исследования. 2021. Т. 10. № 3A. C. 5-17, DOI: 10.34670/AR.2021.11.58.001

2. Воронин А.Н., Горюнова Н.Б. Параметрическая сложность заданий в тестах интеллекта // Психологический журнал. 2020, том 41, № 6, с. 38-46, DOI: 10.31857/S020595920012585-9

3. Воронин А.Н., Горюнова Н.Б. Когнитивный ресурс: структура, динамика и развитие. М.: Институт психологии РАН, 2016, 275 с.

4. Дружинин В.Н. Когнитивные способности: структура, динамика, развитие. М.: ПерСе, СПб: Иматон, 2001, $223 \mathrm{c}$.

\section{Данилова А.В. \\ Особенности совладающего поведения и уровней тревожности студентов}

Крымский инженерно-педагогический университет имени Февзи Якубова (Россия, Симферополь)

doi: 10.18411/trnio-11-2021-213

\section{Аннотация}

Данная статья посвящена особенностям совладающего поведения и уровней тревожности студентов. Автором выявлены специфики копинг-стратегий и психологических защитных механизмов у студентов с различным уровнем тревожности. В статье делается акцент на том, что наиболее эффективные способы совладающего поведения выбирают студенты среднего и низкого уровня тревожности, неэффективные копинг-стратегии применяют студенты с высоким уровнем тревожности.

Ключевые слова: студенты, личность, стресс, страх, тревожность, совладающее поведение, копинг-стратегии. 